\title{
Tingkat Pengetahuan Petugas Pengelola Vaksin dan Evaluasi Pengelolaan Vaksin di Puskesmas Kabupaten Sleman
}

\author{
The Knowledge Level of Vaccine Management Officers and Evaluation of Vaccine Management at \\ The Primary Health Care in Sleman District \\ Septimawanto Dwi Prasetyo ${ }^{*}$, Bunga Carina Vidia Ningrum², Elizabeth Henny Irianingrum ${ }^{2}$, \\ Farras Talitha Oktarini², Ismah Nizza ${ }^{2}$ \\ ${ }^{1}$ Fakultas Farmasi, Universitas Gadjah Mada \\ 2 Program Sarjana Farmasi, Fakultas Farmasi, Universitas Gadjah Mada \\ Corresponding author: Septimawanto Dwi Prasetyo; Email: septimawanto_apt@ugm.ac.id \\ Submitted: 07-10-2020 Revised:24-11-2020 Accepted:25-11-2020
}

\begin{abstract}
ABSTRAK
Vaksin merupakan produk biologis yang sangat rentan sehingga diperlukan pengelolaan vaksin yang tepat untuk menjaga kualitas vaksin. Kualitas vaksin perlu dipertahankan sejak vaksin diproduksi sampai sebelum diberikan kepada pasien. Pengelolaan vaksin yang tepat juga perlu didukung oleh petugas yang terlatih dan bertanggung jawab. Penelitian ini bertujuan untuk mengetahui gambaran pengelolaan vaksin dan tingkat pengetahuan pengelola vaskin di Puskesmas Kabupaten Sleman. Penelitian ini merupakan penelitian observasional yang bersifat deskriptif dengan desain cross-sectional. Data yang dikumpulkan berupa data kuantitatif dan kualitatif yang diperoleh dari enam puskesmas di Kabupaten Sleman. Pengumpulan data diperoleh dari observasi langsung, wawancara, dan pengisian kuesioner. Data kemudian dianalisis secara statistik berupa persentase. Data disajikan dalam bentuk tabel dan narasi yang menggambarkan pengelolaan vaksin dan tingkat pengetahuan pengelola vaksin. Pada penelitian ini diketahui bahwa tingkat pengetahuan petugas pengelola vaksin tergolong baik. Aspek tingkat pengetahuan yang tergolong baik adalah aspek penyimpanan, pelayanan, pencatatan dan pelaporan vaksin, sedangkan aspek perencanaan, pengendalian dan distribusi vaksin tergolong kurang baik. Pada penelitian ditemukan bahwa semua aspek pengelolaan vaksin sudah tergolong baik, namun masih ditemukan beberapa hal yang kurang baik. Sebanyak 28\% puskesmas mengalami over stock vaksin dan $40 \%$ puskesmas belum menyimpan vaksin dengan memberi jarak antar kotaknya. Masih terdapat $72 \%$ puskesmas memiliki vaksin yang kedaluwarsa dan $36 \%$ belum mencatat suhu vaksin pada saat libur.
\end{abstract}

Kata kunci: pengelolaan vaksin; pengelola vaksin; tingkat pengetahuan; puskesmas

\begin{abstract}
Vaccines are biological products that are very vulnerable so vaccine management is needed to keep quality of vaccine. The quality of vaccines needs to be maintained from the time the vaccine is produced until it is administered to the patient. Vaccine management also needs to be supported by trained and responsible healthcare staff. This study aimed to determine vaccine management and the knowledge level of vaccine management officer in the first level healthcare facilities in the Sleman region.This study is an observational descriptive study with cross-sectional design. Quantitative and qualitative data were obtained from six of first level health facilities in the Sleman. Data collection was obtained from direct observation, interviews, and filling out questionnaires. The data then analyzed statistically in the form of a percentage. Data was presented in tabular and narrative form that describe vaccine management and vaccine management officer knowledge level. In this study it was known that the knowledge of vaccine management officers was good. Aspects of knowledge that were classified as good were aspects of storage, use, recording and reporting of vaccines, while aspects of planning,vaccine distribution and control were not good. As many as $28 \%$ of first level healthcare facilities had over-stock of vaccines and $40 \%$ of study subjects did not save the vaccine by giving distance between the boxes. There are still $72 \%$ of research subjects having outdated vaccines and $36 \%$ have not recorded temperature during holidays.
\end{abstract}

Keywords: vaccine management; vaccine management officer; knowledge level; health facilities

\section{PENDAHULUAN}

Pengelolaan vaksin di puskesmas membutuhkan penanganan khusus oleh tenaga kesehatan. Sistem rantai dingin atau cold chain berguna untuk memelihara dan menjamin mutu vaksin dalam pendistribusian mulai dari pabrik pembuat vaksin sampai pada pasien. Pengelolaan vaksin harus dilakukan secara tepat karena adanya kesalahan dalam pengelolaan dapat menyebabkan terhambatnya 
program imunisasi, tidak tercapai target imunisasi, dan pemborosan uang (Kementerian Kesehatan Republik Indonesia, 2017).

Pengelolaan vaksin di puskesmas masih perlu diperhatikan secara khusus. Dari hasil penelitian, diketahui terdapat banyak peralatan rantai dingin vaksin yang tidak dikelola secara benar sehingga banyak terjadi kerusakan vaksin. Hasil penelitian yang lain terkait dengan tingkat pengetahuan tenaga kesehatan, terdapat $77,3 \%$ dari 22 responden tidak tahu metode yang baik untuk menyimpan vaksin dan $59,1 \%$ dari 22 responden tidak mengetahui penempatan termometer yang tepat di unit penyimpanan vaksin (Utoro, Masria and Trisnadi, 2017).

Vaksin tidak dapat dipertahankan kondisinya apabila tidak didukung dengan petugas yang terlatih sebagai pengelolanya. Pengelola vaksin perlu mengetahui bagaimana pengelolaan vaksin yang tepat. Pengelolaan vaksin perlu dilakukan dengan benar dan tepat untuk menjaga kualitas vaksin selama proses distribusi dan penyimpanan. Penelitian ini akan mendeskripsikan tingkat pengetahuan pengelola vaksin dan bagaimana pengelolaan vaksin di Puskesmas Kabupaten Sleman. Penelitian ini dikembangkan dengan harapan dapat dijadikan bahan evaluasi sehingga dapat meningkatkan kualitas pelayanan kesehatan di Puskesmas Kabupaten Sleman.

\section{METODOLOGI}

Penelitian ini merupakan suatu penelitian observasional dengan desain penelitian cross-sectional. Penelitian ini dilakukan di Puskesmas Kabupaten Sleman dengan subjek penelitian sebanyak 25 Puskesmas.

Responden dalam penelitian ini adalah pengelola obat di instalasi farmasi di Puskesmas Kabupaten Sleman dengan total 27 orang, hal ini karena terdapat 2 puskesmas dengan pengelola vaksin sebanyak 2 orang.

Data dikumpulkan melalui observasi di unit pelayanan farmasi puskesmas berupa checklist, wawancara, dan pengisian kuesioner oleh petugas pengelola vaksin. Validasi kuesioner yang dilakukan berupa validitas konten meliputi penilaian para ahli dan validitas muka. Data yang dikumpulkan berupa data kuantitatif dan kualitatif. Data kuantitatif dianalisis secara statistik berupa persentase dan data kualitatif disajikan dalam bentuk narasi.

\section{HASIL DAN PEMBAHASAN Tingkat Pengetahuan Responden Karakteristik Responden}

Responden pada penelitian ini adalah sebanyak 27 responden. Karakteristik yang diukur dalam penelitian ini meliputi usia, pendidikan terakhir, jenis tenaga kesehatan, dan lama bekerja sebagai pengelola vaksin yang ditunjukkan pada Tabel I.

Karakteristik responden adalah mayoritas yang berada dalam kelompok usia > 30 tahun $(62,96 \%)$ dan memiliki pendidikan terakhir profesi apoteker (66,67\%). Hal ini sudah sesuai dengan kualifikasi petugas cold chain yaitu minimal berpendidikan SMA atau SMK berdasarkan PMK No. 12 tahun 2017 tentang penyelenggaraan imunisasi. Selain itu, mayoritas responden telah bekerja sebagai pengelola vaksin selama $\leq 1$ tahun $(55,56 \%)$ dan berprofesi sebagai apoteker (70,37\%). Dari 25 puskesmas didapati bahwa hanya 3 (16,67\%) puskesmas yang pengelola vaksinnya masih dipegang oleh bidan sementara yang lainnya sudah dipegang oleh bagian farmasi.

Menurut wawancara dengan responden, Dinas Kesehatan Kabupaten Sleman pada tahun 2017 telah mengeluarkan peraturan bahwa pengelolaan vaksin diserahkan ke bagian farmasi dan dipegang oleh apoteker/asisten apoteker. Penyerahan pengelolaan vaksin ke bagian farmasi ini untuk menerapkan sistem kebijakan satu pintu (one gate policy) dipuskesmas sehingga memudahkan dalam keluar masuknya obat. Berbeda halnya dengan penelitian yang dilakukan oleh Permatasari yang diketahui hanya 2 puskesmas kecamatan (20\%) yang menerapkan kebijakan satu pintu sampai tingkat puskesmas kelurahan, sedangkan 8 puskesmas kecamatan lainnya menerapkan kebijakan satu pintu ini hanya sampai puskesmas kecamatan (Permatasari, 2018).

\section{Tingkat Pengetahuan Responden}

Menurut Notoatmodjo (2014) bahwa pengetahuan adalah hasil tahu seseorang menggunakan indera yang dimiliki terhadap suatu objek. Pengetahuan setiap orang terhadap suatu obyek berbeda-beda tengantung dengan penginderaannya (Masturoh and Nauri, 2018). Pengetahuan berperan penting terhadap kehidupan dan perkembangan individu, masyarakat, atau organisasi (Sanifah, 2018). Dalam hal ini, pengetahuan pengelola vaksin 
Tabel I. Karakteristik Responden

\begin{tabular}{lcc}
\hline Karakteristik & Jumlah Responden (n=27) & Persentase Jumlah Responden(\%) \\
\hline Usia & 10 & 37,04 \\
$\quad<30$ tahun & 17 & 62,96 \\
$>30$ tahun & & \\
Pendidikan terakhir & 8 & 29,63 \\
$\quad$ D3 (Farmasi, Kebidanan) & 18 & 66,67 \\
Profesi Apoteker & 1 & 3,70 \\
S2 & & \\
Lama bekerja sebagai & 15 & 55,56 \\
pengelola vaksin & 12 & 44,44 \\
$\quad<1$ tahun & & \\
$>1$ tahun & 3 & 11,11 \\
Jenis tenaga kesehatan & 5 & 18,52 \\
Bidan & 19 & 70,37 \\
Asisten Apoteker & & \\
Apoteker & & \\
\hline
\end{tabular}

Tabel II. Hasil Akhir Tingkat Pengetahuan

\begin{tabular}{lcccc}
\hline Aspek & Nilai tertinggi & Nilai terendah & Rata-rata & Kategori \\
\hline Perencanaan & 100 & 25 & 67,59 & Kurang Baik \\
Pengendalian dan Distribusi & 100 & 0 & 60,49 & Kurang Baik \\
Penyimpanan & 100 & 66,67 & 83.95 & Baik \\
Pelayanan & 100 & 25 & 75.62 & Baik \\
Pencatatan dan Pelaporan & 100 & 33,33 & 80.25 & Baik \\
Seluruh aspek & 95 & 53,33 & 73.58 & Kurang Baik \\
\hline
\end{tabular}

dapat mempengaruhi perilaku petugas dalam melakukan praktik pengelolaan vaksin.

Sebagai tempat penyimpanan akhir vaksin sebelum diberikan kepada pasien, pengelola vaksin di puskesmas harus memiliki pengetahuan yang memadai untuk mengelola vaksin (Mavimbe and Bjune, 2007). Petugas dengan pengetahuan yang kurang mempunyai risiko 3,7 kali menyebabkan kualitas pengelolaan vaksin menjadi buruk dibanding petugas dengan pengetahuan baik (Kristini, 2008). Pengukuran tingkat pengetahuan pada penelitian ini menggunakan kuesioner dengan pertanyaan obyektif berupa multiple choice terkait pengelolaan vaksin yang diisi oleh pengelola sediaan vaksin di Puskesmas Kabupaten Sleman.

Berdasarkan Tabel II menunjukkan terdapat dua aspek pengelolaan yang memiliki hasil kurang baik yaitu aspek perencanaan dan aspek pengendalian dan distribusi vaksin. Diketahui rata-rata pada aspek perencanaan vaksin yaitu 67,59 dengan nilai terendah yaitu
25, hasil tersebut tergolong kurang baik. Hal ini dapat disebabkan terdapat responden apoteker di beberapa puskesmas tidak melakukan perencanaan imunisasi vaksin sehingga tingkat pengetahuan responden apoteker mengenai perencanaan vaksin kurang baik. Hal ini juga dapat diakibatkan kurangnya pelatihan pengelola vaksin terkait perencanaan vaksin dan kurangnya pengalaman kerja pengelola vaksin dalam perencanaan vaksin. Pada aspek pengendalian dan distribusi vaksin didapatkan rata-rata sebesar 60,47 dengan nilai terendah didapatkan pada responden dengan hasil 0 , hasil tersebut tergolong kurang baik. Berdasarkan Tabel II menunjukkan bahwa seluruh aspek pengelolaan vaksin memiliki nilai tertinggi 100. Hasil tertinggi didapatkan pada responden dengan nilai 95 dan hasil terendah didapatkan oleh responden dengan nilai 53,33. Secara keseluruhan rata-rata tingkat pengetahuan responden terkait pengelolaan vaksin kurang baik, yaitu 73,58 . 
Tabel III. Perencanaan Vaksin

\begin{tabular}{llcc}
\hline \multirow{2}{*}{ No } & \multicolumn{1}{c}{ Item } & \multicolumn{2}{c}{ Total } \\
\cline { 3 - 4 } & $\begin{array}{c}\text { Ya } \\
\mathbf{n}(\%)\end{array}$ & $\begin{array}{c}\text { Tidak } \\
\text { n (\%) }\end{array}$ \\
\hline 1. & $\begin{array}{l}\text { Perencanaan vaksin sudah mencakup vaksin untuk imunisasi } \\
\text { dasar }\end{array}$ & $25(100)$ & $0(0)$ \\
2. & $\begin{array}{l}\text { Perencanaan vaksin sesuai dengan kebutuhan penggunaan } \\
\text { vaksin di puskesmas }\end{array}$ & $23(92)$ & $2(8)$ \\
3. & $\begin{array}{l}\text { Perencanaan ADS (Auto Disposable Syringe) mencukupi } \\
\text { kebutuhan yang mencakup jenis ADS yaitu 0,05 mL; 0,5 mL; dan }\end{array}$ & $25(100)$ & $0(0)$ \\
& $\begin{array}{l}5 \text { mL } \\
\text { 4. }\end{array}$ & $25(100)$ & $0(0)$ \\
\hline
\end{tabular}

\section{Pengelolaan Vaksin Perencanaan Vaksin}

Hasil observasi menunjukkan bahwa perencanaan vaksin di seluruh puskesmas sudah mencakup vaksin imunisasi dasar. Hal ini diketahui dari LPLPV yang menunjukkan bahwa sudah dilakukan perencanaan untuk vaksin BCG, DPT-HB-Hib, IPV, HB-Uniject, dan vaksin Measles Rubela (MR). Hal ini sesuai dengan PMK Nomor 12 Tahun 2017 tentang Penyelenggaraan Imunisasi yaitu vaksin imunisasi dasar lengkap yang ada di Indonesia meliputi BCG, DPT-HB-Hib, polio/IPV, dan MR (Kementerian Kesehatan Republik Indonesia, 2017).

Hasil observasi menunjukkan bahwa perencanaan vaksin di 23 puskesmas (92\%) sudah disesuaikan dengan penggunaan vaksin di puskesmas. Dalam perencanaan kebutuhan vaksin, puskesmas sudah memperhitungkan jumlah penggunaan vaksin pada bulan sebelumnya. Selain itu, menurut PMK Nomor 12 tahun 2017 tentang Penyelenggaraan Imunisasi, perencanaan kebutuhan logistik vaksin yaitu Auto Disposable Syringe (ADS) dan safety box juga merupakan salah satu aspek yang perlu diperhatikan dalam tahap perencanaannya. Seluruh puskesmas (100\%) memiliki perencanaan ADS dengan beberapa jenis ukuran yang sudah mencukupi kebutuhan serta safety box telah disesuaikan dengan kebutuhan limbah yang dihasilkan. Hasil tersebut berbeda dengan hasil penelitian yang dilakukan oleh Merindani dkk di Puskesmas Suboh yang menunjukkan bahwa Puskesmas Suboh tidak melakukan perencanaan alat suntik dan safety box karena sudah ditentukan dari Dinas Kesehatan (Merindani, Nuryadi and Witcahyo, 2015).

Dari keseluruhan item yang terdapat pada Tabel III, diketahui bahwa rata-rata pengelolaan vaksin terkait aspek perencanaan vaksin adalah sebesar 98\%. Pengelolaan vaksin terkait aspek perencanaan vaksin di puskesmas yang terletak di Kabupaten Sleman sudah tergolong baik.

\section{Penyimpanan Vaksin}

Observasi terhadap penyimpanan vaksin dilakukan melalui pengamatan terhadap unit penyimpanan dan peralatan vaksin, ketersediaan sumber listrik dan generator, serta penataan vaksin dalam unit penyimpanan. Penyimpanan vaksin yang diamati adalah penyimpanan vaksin yang terdapat dalam vaccine refrigerator di puskesmas.

Unit penyimpanan dan peralatan yang diperlukan dalam penyimpanan vaksin antara lain vaccine refrigerator, cool packs, termometer, danfreeze tag. Tabel IV menunjukkan hasil bahwa seluruh puskesmas memiliki vaccine refrigerator yang dapat berfungsi dengan baik dengan tipe top opening. Menurut PMK Nomor 12 tahun 2017 tentang Penyelenggaraan Imunisasi, vaccine refrigerator tipe top opening lebih direkomendasikan, sebab dapat menyimpan suhu lebih stabil serta dapat menampung jumlah vaksin yang lebih banyak dibandingkan tipe front opening.

Tabel IV menunjukkan bahwa di semua puskesmas sudah tersedia cool pack yang mencukupi. Semua puskesmas sudah memiliki termometer yang fungsional di dalam vaccine refrigerator dan suhu di dalam vaccine refrigerator pada saat dilakukan penelitian sudah sesuai yaitu pada rentang suhu $2^{\circ} \mathrm{C}-8^{\circ} \mathrm{C}$. Sejumlah 96\% puskesmas memiliki freeze tag yang berfungsi dengan baik dalam vaccine refrigerator. Kondisi freeze tag dapat diamati dari berubahnya tanda pada freeze tag. Apabila tanda pada freeze tag berubah dari centang $(\sqrt{ })$ 
Tabel IV. Penyimpanan Vaksin

\begin{tabular}{clcc}
\hline \multirow{2}{*}{ No } & \multicolumn{1}{c}{ Item } & \multicolumn{2}{c}{ Total } \\
\cline { 3 - 4 } & & $\begin{array}{c}\text { Ya } \\
\mathbf{n}(\mathbf{\%})\end{array}$ & $\begin{array}{c}\text { Tidak } \\
\text { n (\%) }\end{array}$ \\
\hline 1. & Tersedia vaccine refrigerator yang berfungsi dengan baik & $25(100)$ & $0(0)$ \\
2. & Terdapat cool packs yang mencukupi & $25(100)$ & $0(0)$ \\
3. & Terdapat termometer yang fungsional di dalam vaccine & $25(100)$ & $0(0)$ \\
& refrigerator & $24(96)$ & $1(4)$ \\
4. & Tersedia freeze tag yang fungsional & $25(100)$ & $0(0)$ \\
5. & Sumber energi listrik selalu tersedia 24 jam & $25(100)$ & $0(0)$ \\
6. & Tersedia satu unit generator otomatis atau manual yang selalu & & \\
& siap untuk beroperasi bila listrik padam & $15(60)$ & $10(40)$ \\
7. & Terdapat jarak antara kotak vaksin sekitar 1-2 cm pada & $23(92)$ & $2(8)$ \\
& penyimpanan vaksin dalam vaccine refrigerator & $23(92)$ & $2(8)$ \\
8. & Vaksin heat sensitive diletakkan dekat evaporator & $25(100)$ & $0(0)$ \\
9. & Vaksin freeze sensitive diletakkan jauh dari evaporator & & \\
10. & Vaksin disusun berdasarkan kondisi VVM vaksin, EEFO, FIFO & &
\end{tabular}

menjadi tanda silang $(\mathrm{X})$ maka artinya vaksin telah terpapar suhu beku sehingga perlu dilakukan shake test (Kementerian Kesehatan Republik Indonesia, 2017).

Sumber utama tenaga yang digunakan $\mathrm{di}$ semua puskesmas adalah listrik dan sudah tersedia selama 24 jam. Selain itu, generator juga tersedia di semua puskesmas untuk mengantisipasi apabila terjadi listrik padam. Terdapat tiga belas puskesmas yang memiliki generator otomatis dan terdapat dua belas puskesmas yang memiliki generator manual. Puskesmas dengan generator manual memiliki petugas yang akan segera menyalakan generator apabila listrik padam.

Penataan vaksin pada refrigerator merupakan hal yang tidak kalah penting dalam penyimpanan vaksin. Sebesar $60 \%$ puskesmas memberikan jarak antar kotak vaksin dalam refrigerator sekitar 1-2 cm. Adanya jarak antar vaksin dapat memberikan ruang sirkulasi udara dalam refrigerator sehingga udara dingin dalam refrigerator dapat terdistribusi merata dan dapat membantu vaksin mempertahankan suhu dengan konsisten.

Sejumlah $92 \%$ puskesmas sudah meletakkan vaksin HS (Heat Sensitive) dekat dengan evaporator. Vaksin HS yang tersedia di puskesmas antara lain vaksin BCG dan campak. Begitu juga dengan vaksin FS (Freeze Sensitive), sejumlah $92 \%$ puskesmas sudah meletakkan vaksin FS jauh dari evaporator. Vaksin FS yang tersedia di puskesmas antara lain vaksin IPV, DT, DPT-HB-Hib, HB, dan Td. Berdasarkan PMK
Nomor 12 tahun 2017 tentang Penyelenggaraan Imunisasi, terdapat ketentuan lain yang harus selalu diperhatikan dalam penyimpanan vaksin yakni penyimpanan vaksin disusun menggunakan sistem EEFO (Earliest Expire First Out) dan FIFO (First in First Out). Hasil penelitian berdasarkan wawancara menunjukkan bahwa seluruh puskesmas sudah menyimpan vaksin sesuai dengan prinsip EEFO dan FIFO.

\section{Ketersediaan dan Distribusi Vaksin}

Proses distribusi vaksin dari pusat sampai ke tingkat pelayanan, harus mempertahankan kualitas vaksin tetap tinggi agar mampu memberikan kekebalan yang optimal kepada sasaran. Proses distribusi ini berkaitan erat dengan ketersediaan vaksin yang ada di puskesmas. Hasil observasi terkait ketersediaan dan distribusi vaksin ditunjukkan pada Tabel V.

Pendistribusian vaksin dari dinas kesehatan kabupaten/kota ke puskesmas dilakukan setiap satu bulan sekali dan tidak pernah terjadi keterlambatan. Berdasarkan Tabel V ditunjukkan bahwa semua puskesmas (100\%) telah memiliki vaccine carrier/cold box yang dapat berfungsi dengan baik sehingga item pengelolaan ini tergolong baik. Hal ini sesuai dengan penelitian yang dilakukan oleh Maksuk (2012) di Kota Palembang yang juga mengatakan bahwa dari 14 puskesmas, semuanya telah mempunyai vaccine carrier/cold box (Maksuk, 2012). 
Tabel V. Ketersediaan dan Distribusi Vaksin

\begin{tabular}{clcc}
\hline \multirow{2}{*}{ No } & \multicolumn{1}{c}{ Item } & \multicolumn{2}{c}{ Total } \\
\cline { 3 - 4 } & & $\begin{array}{c}\text { Ya } \\
\mathbf{n}(\%)\end{array}$ & $\begin{array}{c}\text { Tidak } \\
\text { n (\%) }\end{array}$ \\
\hline 1. & Terdapat vaccine carrier/cold box yang berfungsi dengan baik dan & $25(100)$ & $0(0)$ \\
& mencukupi & & \\
2. & Pendistribusian vaksin dari puskesmas ke tempat pelayanan & $25(100)$ & $0(0)$ \\
& menggunakan vaccine carrier yang disertai dengan cool pack & & \\
3. & Jenis vaksin imunisasi dasar yang tersedia di puskesmas & \\
& BCG & $25(100)$ & $0(0)$ \\
& IPV & $25(100)$ & $0(0)$ \\
& MR & $25(100)$ & $0(0)$ \\
& DPT/HB/HIB Pentavalen & $25(100)$ & $0(0)$ \\
HB Uniject & $25(100)$ & $0(0)$ \\
4. & Tidak terdapat stock out vaksin yaitu jumlah stok akhir adalah nol & $22(88)$ & $3(12)$ \\
5. & Tidak terdapat over stock vaksin yang berarti yaitu stok vaksin & $18(72)$ & $7(28)$ \\
& yang kecukupan vaksinnya lebih dari 1 bulan + 1 minggu & & \\
6. Tidak terdapat vaksin yang kedaluwarsa selama 6 bulan terakhir & $7(28)$ & $18(72)$ \\
\hline
\end{tabular}

Hasil penelitian semua puskesmas (100\%) mempunyai vaksin BCG, IPV, MR, Td, HB Uniject, dan DPT/HB/HIB Pentavalen, yang tergolong vaksin imunisasi dasar. Hal ini sesuai dengan vaksin imunisasi dasar lengkap yang ada di Indonesia yang meliputi BCG, DPT-HBHib, polio/IPV, dan campak.

Tabel V menunjukkan bahwa tidak terdapat stock out vaksin pada 22 (88\%) puskesmas, sehingga dapat dikatakan bahwa pengelolaan terkait hal ini adalah baik. Selain stock out, diketahui juga terdapat over stock vaksin pada 7 (28\%) puskesmas, sehingga dapat dikatakan bahwa pengelolaan vaksin terkait hal ini adalah kurang baik.

Berdasarkan Tabel $\mathrm{V}$ diketahui bahwa selama 6 bulan terakhir 7 (28\%) puskesmas memiliki vaksin yang kedaluwarsa, sehingga dapat dikatakan pengelolaan vaksin terkait hal ini adalah kurang baik. Penyebab dari vaksin kedaluwarsa adalah karena vaksin yang dikirimkan dalam pendistribusian dari Dinas Kesehatan Kabupaten Sleman memiliki kedaluwarsa yang pendek. Penelitian ini serupa dengan penelitian yang dilakukan Panjaitan dkk (2016) yaitu ditemukan sebanyak $36,7 \%$ vaksin kedaluwarsa di Puskesmas Helvetia (Panjaitan, Sembiring and Febriyanti, 2016).

\section{KESIMPULAN}

Pengelolaan vaksin di Puskesmas Kabupaten Sleman cukup baik dengan sebagian besar aspek pengelolaan vaksin telah sesuai dengan standar yang telah ditetapkan oleh WHO dan Kementerian Kesehatan Republik Indonesia. Beberapa aspek pengelolaan vaksin di Puskesmas Kabupaten Sleman yang masih kurang, antara lain 40\% subyek penelitian belum memberi jarak dalam mengatur tata letak vaksin dan $28 \%$ subyek penelitian masih mengalami kondisi overstock, serta $36 \%$ subyek penelitian belum melakukan pencatatan suhu pada hari libur. Pengetahuan pengelola sediaan vaksin di Puskesmas Kabupaten Sleman terkait pengelolaan vaksin cukup baik. Beberapa hal yang masih kurang yaitu terkait perencanaan vaksin, pengendalian dan distribusi vaksin. Rata-rata tingkat pengetahuan pengelola sediaan vaksin di Puskesmas Kabupaten Sleman Bagian kurang baik yaitu sebesar 73,58.

\section{UCAPAN TERIMA KASIH}

Terima kasih kepada petugas kesehatan di Puskesmas Kabupaten Sleman yang turut serta membantu dalam penelitian. Terimakasih pula penulis ucapkan kepada Fakultas Farmasi atas bantuan dana untuk penelitian ini melalui Hibah Penelitian Fakultas Farmasi UGM 2019.

\section{DAFTAR PUSTAKA}

Kementerian Kesehatan Republik Indonesia (2017) Peraturan Menteri Kesehatan Republik Indonesia Nomor 12 Tahun 2017 tentang Penyelenggaraan Imunisasi. Jakarta. doi: 10.1002/ejsp.2570.

Kristini, T. D. (2008) 'Faktor-faktor Risiko 
Kualitas Pengelolaan Vaksin Program Imunisasi yang Buruk di Unit Pelayanan Swasta (Studi Kasus di Kota Semarang)', pp. 1-176.

Maksuk (2012) 'Pengelolaan Rantai Dingin Vaksin Tingkat Puskesmas di Kota Palembang Tahun 2011', Jurnal Kesehatan Poltekkes Palembang, 1(10), pp. 94-100.

Masturoh, I. and Nauri, A. T. (2018) Bahan Ajar Rekam Medis dan Informasi Kesehatan: Metodologi Penelitian Kesehatan, Edisi Tahun 2018.

Mavimbe, J. C. de T. and Bjune, G. (2007) 'Cold Chain Management: Knowledge and Practices in Primary Health Care Facilities in Niassa, Mozambique', Ethiopian Journal of Health Development, 21(2), pp. 130-135. doi: 10.4314/ejhd.v21i2.10040.

Merindani, W. S., Nuryadi and Witcahyo, E. (2015) 'Kajian Manajemen Penyelenggaraan Program Imunisasi
Difteri di Puskesmas Suboh Kabupaten Situbondo', Artikel Ilmiah Hasil Penelitia Mahasiswa.

Panjaitan, M., Sembiring, R. and Febriyanti (2016) 'Hubungan Penyimpanan Vaksin dengan Kerusakan Vaksin di Puskesmas Helvetia tahun 2015', Reproductive Health, 1(2), pp. 29-40.

Permatasari, D. (2018) 'Evaluasi Implementasi Managemen Vaksin di Suku Dinas Kesehatan Jakarta Timur dan Jajarannya', (5), pp. 2-4.

Sanifah, L. J. (2018) 'Hubungan Tingkat Pengetahuan dengan Sikap Keluarga Tentang Perawatan Activities Daily Living (ADL) pada Lansia', Society, pp. 14-18.

Utoro, G. A., Masria, S. and Trisnadi, S. (2017) 'Gambaran Penerapan Rantai Dingin Vaksin Imunisasi Dasar di Purwakarta Tahun 2017', Prosiding Pendidikan Dokter, 2017(2), pp. 136-142. 